\title{
Application of time-temperature superposition principle to Chinese fir orthotropic creep
}

\author{
Hui Peng ${ }^{1,2} \cdot$ Jiali Jiang ${ }^{1} \cdot$ Jianxiong $\mathrm{Lu}^{1} \cdot{\text { Jinzhen } \mathrm{Cao}^{2}}^{2}$
}

Received: 16 January 2017/ Accepted: 29 April 2017/Published online: 3 June 2017

(C) The Japan Wood Research Society 2017

\begin{abstract}
The application of time-temperature superposition principle (TTSP) to orthotropic creep in dry Chinese fir (Cunninghamia lanceolata [Lamb.] Hook.) was investigated through a sequence of short-term tensile creep for longitudinal (L), radial (R), and tangential (T) specimens in the temperature range of $30-150{ }^{\circ} \mathrm{C}$. A visual assessment for the validity of TTSP was carried out by applying the approximated complex plane (ACP). The results showed that TTSP was well matched for $\mathrm{R}$ and $\mathrm{T}$ specimens using horizontal shift factor to construct master curves. As for $\mathrm{L}$ specimen, an additional vertical shift factor was applied to construct a smooth master curve, owing to the temperaturedependent compliance. Based on the application of ACP, the creep model governed by a power law was proposed to successfully depict the master curve for each main anatomy direction. The present study partially provided the firsthand data in verifying the applicability of TTSP of the orthotropic viscoelasticity of Chinese fir wood, and successfully constructed the rheological model to predict the orthotropic
\end{abstract}

Jianxiong $\mathrm{Lu}$

jianxiong@caf.ac.cn

Jinzhen Cao

caoj@bjfu.edu.cn

Hui Peng

penghyx@126.com

Jiali Jiang

jialiwood@caf.ac.cn

1 State Key Laboratory of Tree Genetics and Breeding, Research Institute of Wood Industry, Chinese Academy of Forestry, Beijing 100091, People's Republic of China

2 College of Materials Science and Technology, Beijing Forestry University, Beijing 100083, People's Republic of China creep response. More importantly, the result can function as the base to the structural safety designs for the engineering structures of Chinese fir in practice.

Keywords Chinese fir - Orthotropic creep · Timetemperature superposition principle $\cdot$ Power law model

\section{Introduction}

Wood, like most polymeric materials, exhibits a viscoelastic behavior depending on both temperature and the duration of the applied stress. The time-dependent behavior, such as creep and relaxation, of wood is of critical importance in engineering applications [1-4]. For this reason, it is desirable to investigate the viscoelastic behavior of wood over time scales that extend as long as the working life of wooden products. Unfortunately, practical considerations limit a lengthy creep or relaxation test, and an alternative approach to determine the timedependent behavior of wood is to use the time-temperature superposition principle (TTSP) to obtain an extended range of time. The TTSP is based upon the theory that increasing the temperature is equivalent to stretching the real time of the viscoelastic response [5-9]. In this approach, viscoelastic properties can be determined by static measurements (e.g., creep or stress relaxation) or by dynamic measurements using frequency-multiplexing experiments over a wide range of temperatures. By selecting a reference curve at the desired temperature and shifting the data at other temperatures to the reference temperature (horizontal shifts on the log time or log frequency axis), a master curve is generated over several decades of time or frequency domain. The curve can be used to predict the long-term effects of stress/strain on wood properties. 
The empirical relationship between temperature and time effect of stress/strain on deformation and relaxation processes (i.e., the horizontal shift factor required to transpose the temperature effect to the corresponding time effect) is formulated in two well-known mathematical functions: William-Landel-Ferry (WLF) equation and Arrhenius law. The WLF equation, enunciated by Williams et al. [10], is given by Eq. (1), and the activation energy $(\Delta H)$ can also be expressed by WLF equation using Eq. (2):

$\log a_{T}=-C_{1}\left(T-T_{0}\right) /\left[C_{2}+\left(T-T_{0}\right)\right]$,

$\Delta H=R \cdot d\left(\log a_{T}\right) / d T$,

where $a_{T}$ is the horizontal shift factor on the log time axis to transpose the creep or relaxation value at short time and higher temperature to the appropriate time scale expected at a lower temperature, $T$ the measurement temperature, $T_{0}$ the reference temperature, $C_{1}$ and $C_{2}$ two WLF constants, and $R$ the universal gas constant. The WLF equation describes the time-temperature stress/strain response behavior of a polymer at/near its glass transition temperature, which is suitable to be used for amorphous polymer systems. The Arrhenius law is usually used to relate the horizontal shift factor with respect to temperature and is given by

$\log a_{T}=\Delta H / 2.303 R \cdot\left(1 / T-1 / T_{0}\right)$,

where $a_{T}$ is the horizontal shift factor, $\Delta H$ the activation energy, $T$ the measurement temperature, $T_{0}$ the reference temperature, and $R$ the universal gas constant. The Arrhenius law is typically used to determine the activation energy associated with the glass transition process.

Research has shown that TTSP was originally developed for amorphous polymers. However, wood is a composite biopolymer consisting of cellulose, hemicelluloses and lignin, and the time-dependent behavior of wood is determined by both oriented crystalline cellulose and amorphous matrix made up of lignin and a variety of hemicelluloses. Given multiple transition regions from the thermorheological point, the TTSP's applicability to wood is sometimes controversial [8-15]. Macroscopically, wood is normally described as an anisotropic material with unique and independent mechanical behaviors in three mutually perpendicular directions: longitudinal direction, radial and tangential directions in the transverse plane [16-18]. In general, investigators study of TTSP's applicability to wood mainly focuses on the longitudinal or radial direction, but rarely provides a comprehensive dataset of TTSP's applicability among the three directions.

The objective of this study was to evaluate the applicability of TTSP in longitudinal, radial, and tangential directions for dry wood and observe the orthotropic creep using TTSP. Additionally, a generic creep model applicable in three main anatomy directions for dry wood was identified as well for obtaining the creep behavior over reasonable time periods.

\section{Materials and methods}

\section{Wood material}

Specimens for creep tests were cut successively within the same growth ring ranges and free of any visual defects in the heartwood part of Chinese fir (Cunninghamia lanceolata [Lamb.] Hook.) logs. Specimens with longitudinal (L), radial $(\mathrm{R})$ and tangential $(\mathrm{T})$ grain directions were prepared as shown in Fig. 1, and the dimension of the specimens was $35 \mathrm{~mm} \times 6 \mathrm{~mm} \times 1.5 \mathrm{~mm}$. All the specimens were dried in a sealed container with anhydrous phosphorus pentoxide $\left(\mathrm{P}_{2} \mathrm{O}_{5}\right)$ at room temperature until no weight loss was observed (not less than 2 weeks). The corresponding moisture content value and raw density of specimens were about $0.6 \%$ and $0.37 \mathrm{~g} / \mathrm{cm}^{3}$, respectively.
Fig. 1 Specimens in three directions. a Longitudinal, b radial, and $\mathbf{c}$ tangential

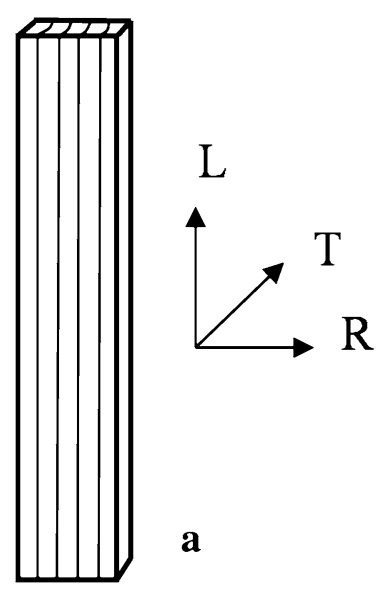

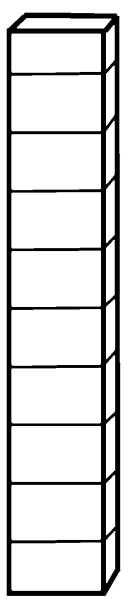

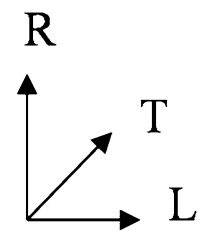

b

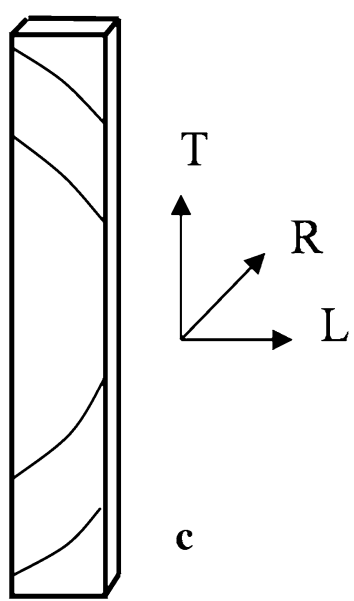




\section{Experimental methods}

Creep behavior was performed on a dynamic mechanical analyzer (DMA 2980, TA Instruments) using a dry air purge of the sample chamber with tensile clamp, and a distance of $17 \mathrm{~mm}$ between clamping midpoints was used (Fig. 2). To make sure the specimen was straight, a preload force of $0.01 \mathrm{~N}$ was applied briefly. Subsequently, each specimen was subjected to isothermal creep segments for $20 \mathrm{~min}$ at each $10{ }^{\circ} \mathrm{C}$ interval in a temperature range of $30-150{ }^{\circ} \mathrm{C}$, and $20 \mathrm{~min}$ equilibration/recovery periods were inserted between creep segments, as illustrated in Fig. 3.

The limit of linearity was determined using a stressstrain sweep, for which the $\mathrm{L}, \mathrm{R}$, and $\mathrm{T}$ specimens were deformed with increasing stress, respectively. Generally,

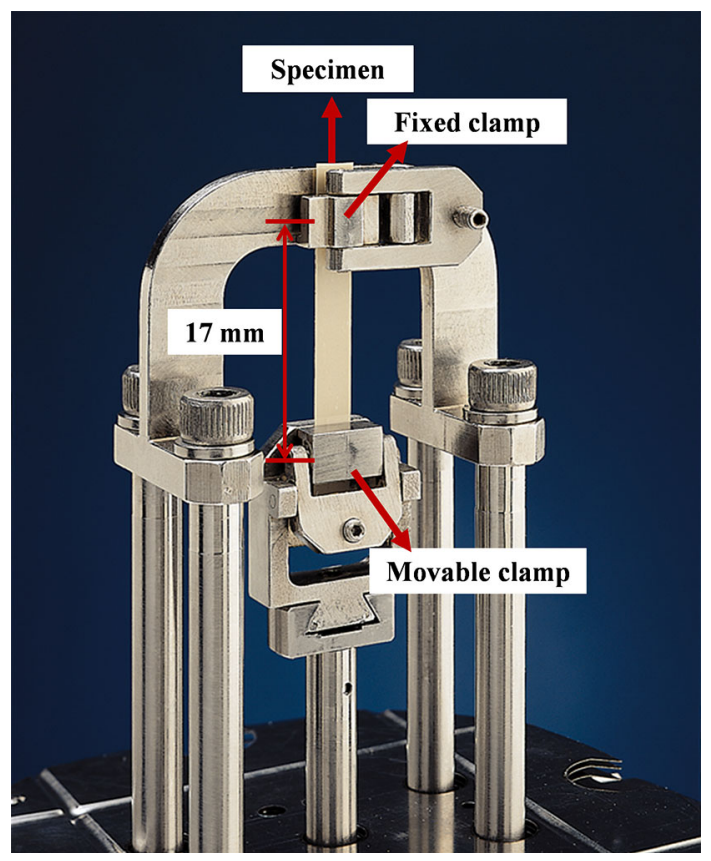

Fig. 2 Illustration of mounted sample ready for tensile mode of loading

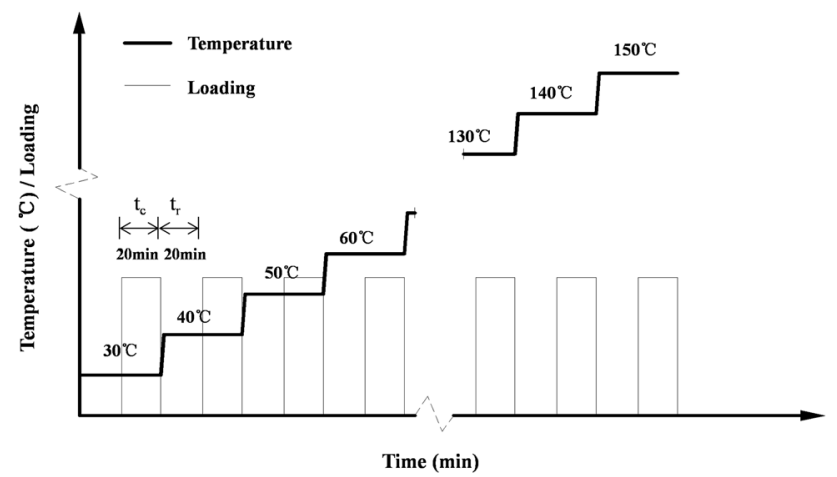

Fig. 3 Applied cycling schedule. $t_{\mathrm{c}}$ Creep time; $t_{\mathrm{r}}$ recovery time wood behaved linearly up to $50 \%$ of the ultimate stress $[2,19]$. Dried specimens were heated to the maximum experimental temperature $150{ }^{\circ} \mathrm{C}$ at $10{ }^{\circ} \mathrm{C} / \mathrm{min}$ and held there for $10 \mathrm{~min}$ before the stress-strain sweep. The ultimate tensile stress of $\mathrm{L}$ specimen was not reached owing to the 2.1 MPa maximum stress of DMA 2980; therefore, the stress value of 1.3 MPa was selected. With regard to the $\mathrm{R}$ and $\mathrm{T}$ specimens, the stress level was set as $20 \%$ of ultimate tensile stress (2.0 $\mathrm{MPa}$ in $\mathrm{R}$ and $0.8 \mathrm{MPa}$ in $\mathrm{T}$ ), i.e., stress values were $0.40 \mathrm{MPa}$, and $0.16 \mathrm{MPa}$ for the $\mathrm{R}$ and $\mathrm{T}$ specimens, respectively.

\section{Data analysis}

A representation relying on the use of the "approximated complex plane" (ACP), proposed by Dlouhá et al. [8], was used to analyze the creep data in this study. This method allowed the data from static tests to be represented in complex plot in the same way as a Cole-Cole graph using complex modulus ( $E^{\prime}$ with respect to $\left.E^{\prime \prime}\right)$ for dynamic tests. According to Alfrey's approximation [20], the storage compliance $J^{\prime}$ and loss compliance $J^{\prime \prime}$ components of complex compliance were applied for static test and can be written as:

$J^{\prime} \approx J(\log t)$,

$J^{\prime \prime} \approx \pi / 2 \cdot d J / d(\ln t) \approx \pi / 2 \ln (10) \cdot d J(\log t) / d \log t$,

where $t$ is the creep time and $J$ the creep compliance.

The ACP is based on a visual assessment of the trajectories in the complex planes $\left(J^{\prime \prime}\right.$ with respect to $\left.J^{\prime}\right)$, which can be understood as a type of phase diagram presenting the slope against the value, relative to the function $J(\log t)$. The assumption of TTSP requires that individual creep curves induce one continuous curve in the ACP, as this would ensure that not only the values of the $J(\log t)$ functions match, but also the slope. Furthermore, the ACP is a convenient way to represent synthesized viscoelastic properties of wood [8].

\section{Results and discussion}

\section{Building of the master curve using $\log t$ shifts}

Short-term experimental data for increasing temperature levels were obtained, and a sequence of curves for $\mathrm{L}, \mathrm{R}$, and $\mathrm{T}$ specimens were plotted as compliance versus time with log scale (Fig. 4). The individual creep curves in the left panel of Fig. 4 represent the creep compliance changes over $20 \mathrm{~min}$ for 13 temperature levels $\left(10^{\circ} \mathrm{C}\right.$ intervals in the range $30-150{ }^{\circ} \mathrm{C}$ ). The curves showed the expected 

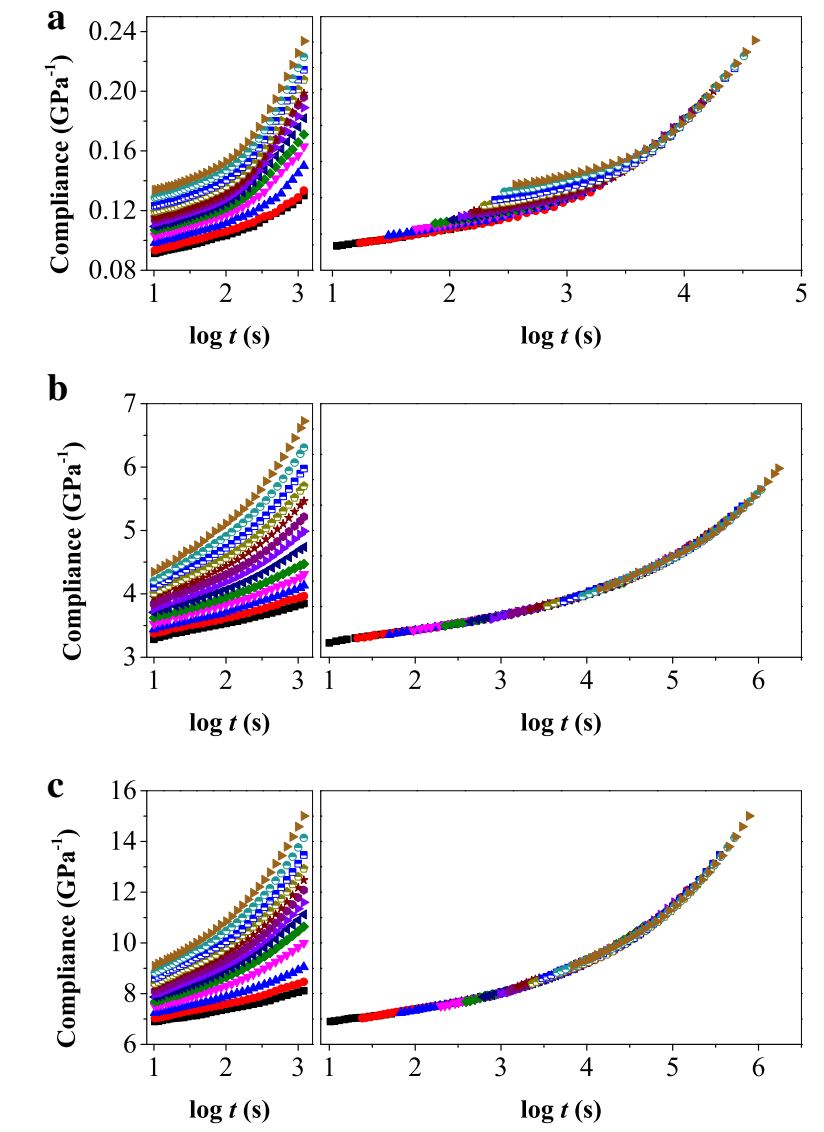

- $30^{\circ} \mathrm{C} \cdot 40^{\circ} \mathrm{C}$ \& $50^{\circ} \mathrm{C}$ - $60^{\circ} \mathrm{C} \rightarrow 70^{\circ} \mathrm{C}$ - $80^{\circ} \mathrm{C}$ > $90^{\circ} \mathrm{C}$

- $100^{\circ} \mathrm{C} * 110^{\circ} \mathrm{C}=120^{\circ} \mathrm{C}=130^{\circ} \mathrm{C}=140^{\circ} \mathrm{C}, 150^{\circ} \mathrm{C}$

Fig. 4 (Right panel) Master curves obtained by shifting individual raw data curves (left panel) along $\log t$ for the $\mathrm{L}(\mathbf{a}), \mathrm{R}(\mathbf{b})$ and $\mathrm{T}$ (c) specimens. Curves measured at $30{ }^{\circ} \mathrm{C}$ are taken as a reference

response from isothermal creep segments: increasing creep compliance with time and temperature for each specimen irrespective of grain orientation [2, 7, 21]. There were differences in compliance among the specimens with three grain orientations. Compliance for $\mathrm{L}$ specimen was significantly lower than that for the $\mathrm{R}$ and $\mathrm{T}$ specimens, and the $\mathrm{T}$ specimen was higher than the $\mathrm{R}$ specimen almost twice. This result was consistent with previous studies $[2,14,22]$. The formation in anatomical structure could explain the differences of wood mechanical behavior among the $\mathrm{L}, \mathrm{R}$, and $\mathrm{T}$ specimens. Tracheids are strictly aligned in the $\mathrm{L}$ direction, which provide mechanical integrity to counteract load and influence the higher stiffness and lower compliance for the L specimen [23, 24]. For the transverse ( $\mathrm{R}$ and $\mathrm{T}$ ) specimens, some researchers stated that ray tissue acting as stiffening ribs in the $\mathrm{R}$ direction contributed to lower compliance comparison with that for the $\mathrm{T}$ specimen [3, 4]. Meanwhile, the cellulose microfibrils are distorted by pits in the $\mathrm{L}$ direction giving the radial cell wall lower compliance [3]. Moreover, the irregular polygonal cell structure in softwood might make the tangential compliance higher $[25,26]$.

The right panel of Fig. 4 demonstrates the master curve that takes $30{ }^{\circ} \mathrm{C}$ as the reference temperature and shifts the raw data curves at other temperatures horizontally along the $\log t$ axis to the $30^{\circ} \mathrm{C}$ curve for each specimen. Thus, from a family of raw data curves at different temperatures, an overlapped master curve was generated for each specimen providing creep compliance values for an extended time period at the reference temperature. The extended time scale of master curves was dependent on grain orientation: the extended time for $\mathrm{R}$ and $\mathrm{T}$ specimens was similar, obviously longer than that for L specimen (Fig. 4). The creep time extrapolated to about $10^{4}, 10^{6}$, and $10^{6} \mathrm{~s}$ from $20 \mathrm{~min}$ isothermal creep test in this study for L, R, and $\mathrm{T}$ specimens, respectively. Furthermore, the overlapping curves of $\mathrm{R}$ and $\mathrm{T}$ specimens were quite well matched than that of the $\mathrm{L}$ specimen.

The horizontal shift factor recorded the horizontal movement for each creep segment and represented the ratio of relaxation times relative to those at the reference temperature (i.e., the shift factor required to transpose the temperature effect to the corresponding time effect). Figure 5 illustrates the horizontal shift factor values of 13 creep curves $\left(30-150{ }^{\circ} \mathrm{C}\right)$ determined in all orthotropic directions, and the increased trend in the magnitude of the horizontal shift factor with elevating temperature was also found. The negative values of the horizontal shift factor indicated that the time needed for a given deformation was reduced and the creep was accelerated at higher temperature.

By fitting the horizontal shift factor data into the WLF equation and Arrhenius law, the solid line and dotted curve were plotted as shown in Fig. 5. Compared to the Arrhenius law, the WLF equation provided a better fitting with the horizontal shift factor over the entire temperature range in all orthotropic directions. The deviation from Arrhenius behavior indicated that a different type of dissipative mechanism occurred during the experiment. In general, standard error values can be used to evaluate the performance of model fitting. Based on Ferry [27], a successful fit result was obtained when the standard error value was less than 20. Table 1 presents the values of $C_{1}$ and $C_{2}$ of the WLF equation based on the horizontal shift factor, as well as the standard error and activation energy calculated from the two mathematical models, respectively. According to the values of standard error, only the excellent fit of the horizontal shift factor to the WLF equation (standard error of estimate $<9.19$ ) was observed under the test condition. The values of activation energy determined by Arrhenius law were lower than those calculated by the WLF equation. This result was in agreement with the earlier study [14]. 

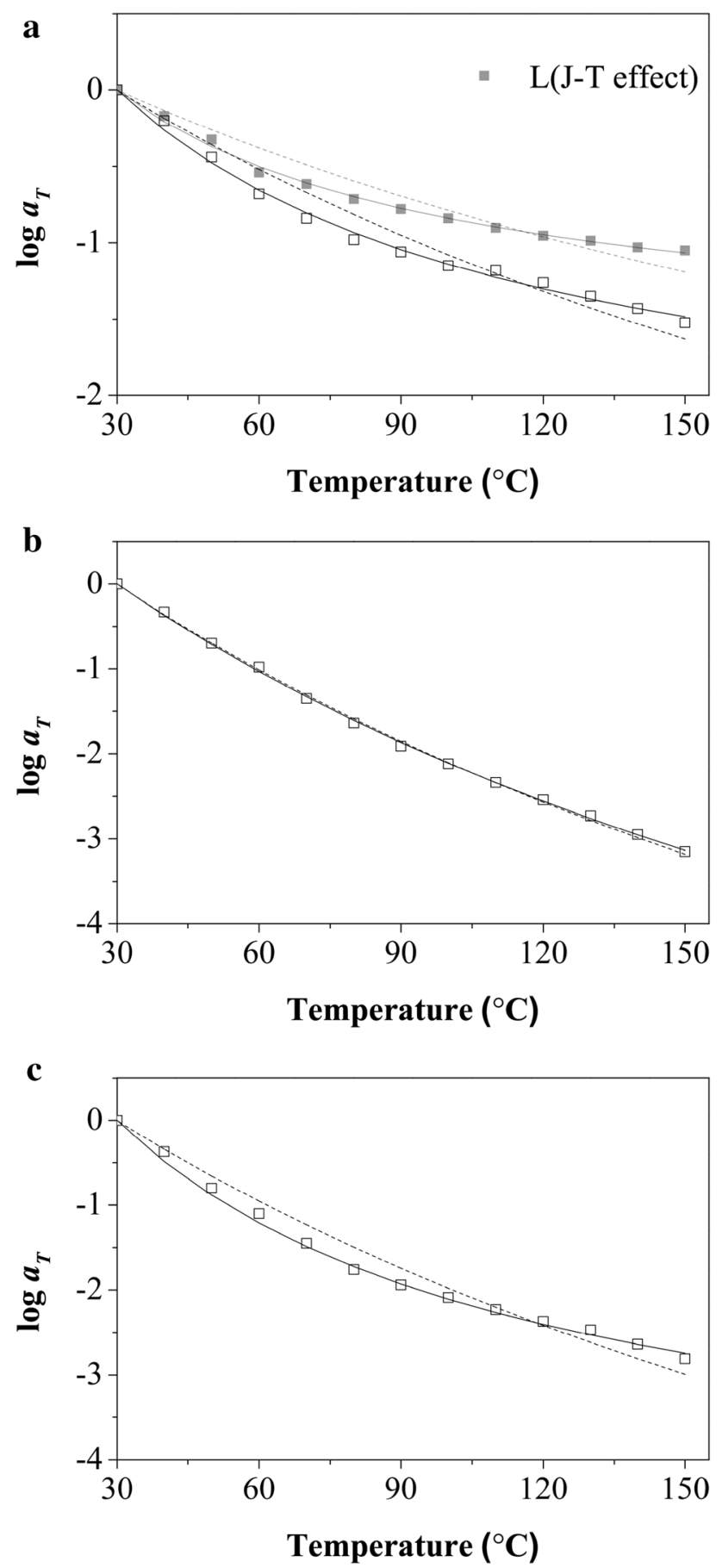

Fig. 5 Horizontal shift factor $a_{T}$ (symbols) used to construct master curves at reference temperature $30{ }^{\circ} \mathrm{C}$ for the $\mathrm{L}(\mathbf{a}), \mathrm{R}(\mathbf{b})$, and $\mathrm{T}$ (c) specimens, and fit of the horizontal shift factor variation to the WLF equation (solid line) and Arrhenius law (dotted line). L ( $\mathrm{J}_{-}$ $T$ effect) in a experimental data corrected by the vertical factor $b_{T}$ for $\mathrm{L}$ specimen

The horizontal shift factor plots between $\mathrm{R}$ and $\mathrm{T}$ specimens were relatively similar, while the $\mathrm{L}$ specimen presented lower absolute value, as shown in Fig. 5. Moreover, the slope of the horizontal shift factor plots in proportion to the activation energy was also different among the $\mathrm{L}, \mathrm{R}$, and $\mathrm{T}$ specimens. The activation energy associates with a mechanism of internal friction, which is defined as the difference in the energy between the atoms or molecules in an activated configuration, and the corresponding atoms or molecules in their initial configurations [14]. The activation energy values for $\mathrm{L}, \mathrm{R}$, and $\mathrm{T}$ specimens are presented in Table 1. According to the WLF equation, the values of activation energy for $\mathrm{L}, \mathrm{R}$, and $\mathrm{T}$ specimens were $12.36,16.21$, and $22.80 \mathrm{kcal} \mathrm{mole}^{-1}$, respectively. Gamalath [28] reported that the activation energy of wood was $16.77-33.77 \mathrm{kcal} \mathrm{mole}^{-1}$. Bond et al. [29] stated that the activation energy of Douglas fir (Pseudotsuga menziesii) at 9\% moisture content was $15.5 \mathrm{kcal} \mathrm{mole}^{-1}$ in tension parallel to the grain. The lower activation energy in the $\mathrm{L}$ specimen may be attributed to the stress modes, reference temperature, moisture content, and grain orientation. In general, the activation energy increased with increasing creep compliance because, as creep increased, greater distortions of bond angles and chain rotations occurred and a larger amount of energy was dissipated, resulting in a higher activation energy [3, 14]. This general trend was in agreement with the largest creep compliance and most activation energy obtained for the $\mathrm{T}$ specimen in this study and was confirmed by Placet et al. [14] as well.

\section{Examination of experimental data in the ACP}

To build a visual assessment of the master curve, the ACP was applied in all directions (Fig. 6). For $\mathrm{R}$ and $\mathrm{T}$ specimens, a continuously linear approximation consisted of the individual creep curves observed in the ACP. However, the ACP showed that the final overlapping was poor for the $\mathrm{L}$ specimen, and the same slope but different intercept of the trajectory with the $J^{\prime}$-axis was found for individual creep curves. The structural arrangement of the wood cell wall can be viewed as a fiber composite system by cellulose microfibrils and hemicellulose-lignin matrix [24, 30]. In tensile tests, highly crystalline cellulose microfibrils dominated the creep behavior of the L specimen, while amorphous hemicellulose-lignin matrix was more pronounced for the $\mathrm{R}$ and $\mathrm{T}$ specimens [30-32]. When tensile stress was applied to the $\mathrm{L}$ specimen, the external stress induced specific molecular deformations of the cellulose microfibrils. The reorientation of cellulose microfibrils and the stretching of the $\mathrm{C}-\mathrm{O}-\mathrm{C}$ bridge between two glucose molecules in a cellulose microfibril caused the cellulose microfibrils to be regularly aggregated toward the cell axis. More importantly, temperature could aggravate the specific molecular deformations of the cellulose microfibrils (i.e., the oriented aggregation), resulting in temperature-dependent compliance (denoted here as the $J-T$ effect) 
Table 1 Parameters of the WLF equation and Arrhenius law for Chinese fir wood in all orthotropic directions

\begin{tabular}{|c|c|c|c|c|c|c|}
\hline \multirow[t]{2}{*}{ Specimens } & \multicolumn{4}{|l|}{ WLF } & \multicolumn{2}{|l|}{ Arrhenius } \\
\hline & $C_{1}$ & $C_{2}(\mathrm{~K})$ & $\Delta H\left(\mathrm{kcal} \mathrm{mole}^{-1}\right)$ & SE $(\%)$ & $\Delta H\left(\mathrm{kcal} \mathrm{mole}^{-1}\right)$ & SE $(\%)$ \\
\hline $\mathrm{L}$ & 2.56 & 87.32 & 12.36 & 9.19 & 8.26 & 32.86 \\
\hline $\mathrm{R}$ & 9.75 & 253.15 & 16.21 & 7.34 & 15.80 & 23.05 \\
\hline $\mathrm{T}$ & 4.74 & 87.55 & 22.80 & 8.64 & 14.96 & 35.86 \\
\hline $\mathrm{L}(J-T$ effect $)$ & 1.71 & 72.02 & 9.97 & 5.97 & 5.86 & 28.53 \\
\hline
\end{tabular}

WLF, William-Landel-Ferry equation, enunciated by Williams et al. [10], is given by $\log a_{T}=-C_{1}(-$ $\left.T-T_{0}\right) /\left[C_{2}+\left(T-T_{0}\right)\right] ; C_{1}$ and $C_{2}$, two WLF constants; $\Delta H$, activation energy deduced from horizontal shift factor plots of raw experimental data; SE, standard error of the estimate; L ( $J-T$ effect), experimental data corrected by the vertical factor $b_{T}$ for $\mathrm{L}$ specimen
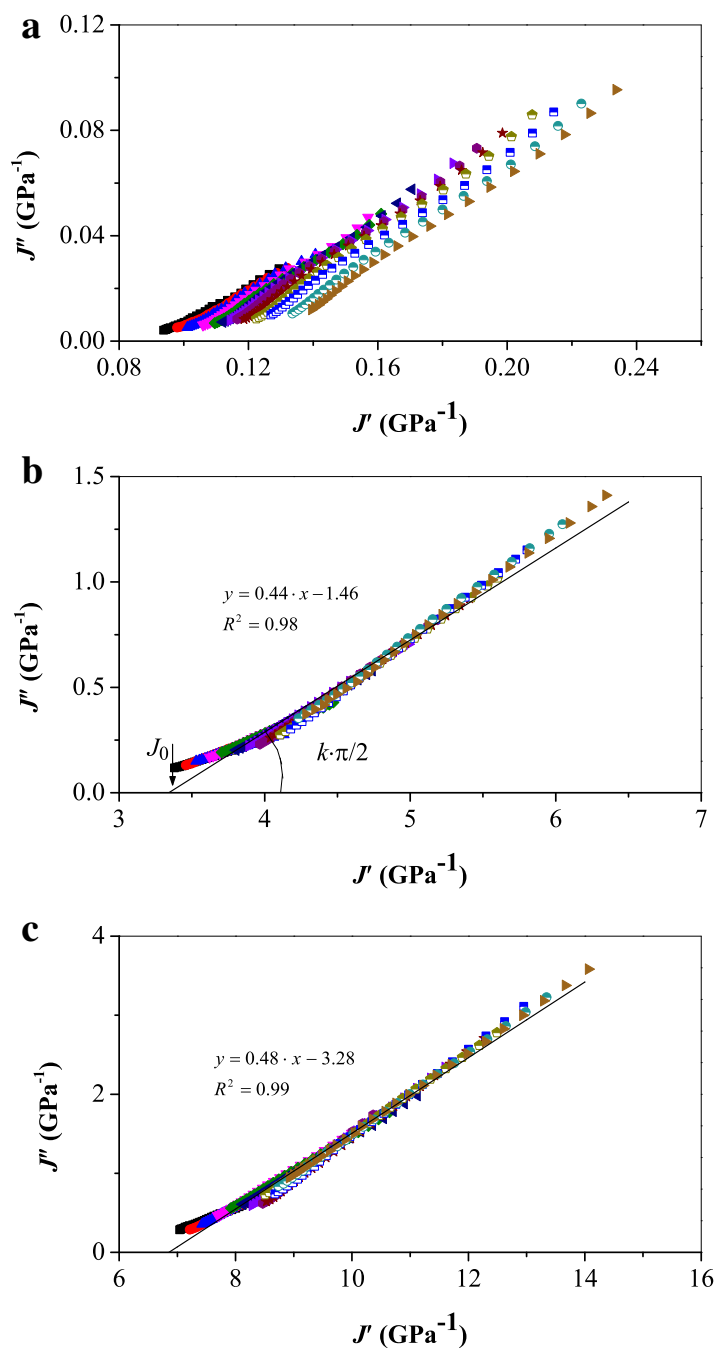

- $30^{\circ} \mathrm{C} \cdot 40^{\circ} \mathrm{C} \wedge 50^{\circ} \mathrm{C} \rightarrow 60^{\circ} \mathrm{C} \rightarrow 70^{\circ} \mathrm{C}+80^{\circ} \mathrm{C} \rightarrow 90^{\circ} \mathrm{C}$

- $100^{\circ} \mathrm{C} \star 110^{\circ} \mathrm{C} \Leftrightarrow 120^{\circ} \mathrm{C}=130^{\circ} \mathrm{C} \theta 140^{\circ} \mathrm{C} \Rightarrow 150^{\circ} \mathrm{C}$

Fig. 6 Representation of the results in the approximated complex plane (ACP) for the L (a), R (b), and T (c) specimens based on Fig. 4. $J^{\prime}$ and $J^{\prime \prime}$ Alfrey's approximations of storage and loss compliance, respectively (Eqs. 4,5$) ; J_{0}$ initial compliance; $k$ power exponent
[24, 33-35]. According to some researches [12, 13, 36, 37], TTSP was applicable to amorphous polymers. The regularly oriented aggregation of highly crystalline cellulose microfibrils with the elevating temperature might result in an additional burden for the application of TTSP. Landel and Nielsen [36] suggested that the TTSP could be applied to most polymers, as long as a vertical shift factor, which was strongly dependent on temperature, was employed. A vertical shift factor $b_{T}$ was introduced in this study accounting for the $J-T$ effect [38], and the corrected compliance $J(t)_{b}$ was written as Eq. (6):

$J(t)_{b}=J(t) / b_{T}$,

where $J(t)$ is the creep compliance.

Based on the $J-T$ effect, a homothetic transformation of longitudinal creep curves in the ACP was performed to eliminate the influence of temperature on compliance. The vertical shift factor $b_{T}$ was adjusted to obtain a continuous curve, taking $30{ }^{\circ} \mathrm{C}$ as the reference temperature. A linear approximation was observed for the transformed ACP $\left(J^{\prime \prime}\right)$ $b_{T}$ with respect to $J^{\prime} / b_{T}$ ) in Fig. 7. Moreover, the

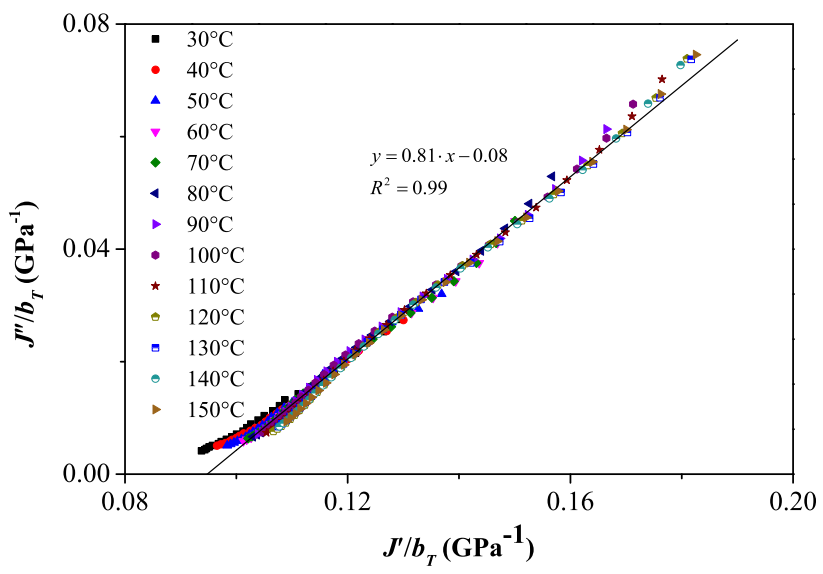

Fig. $7 \mathrm{ACP}$ of the L specimen in Fig. 6 corrected by vertical factors $b_{T}$ 


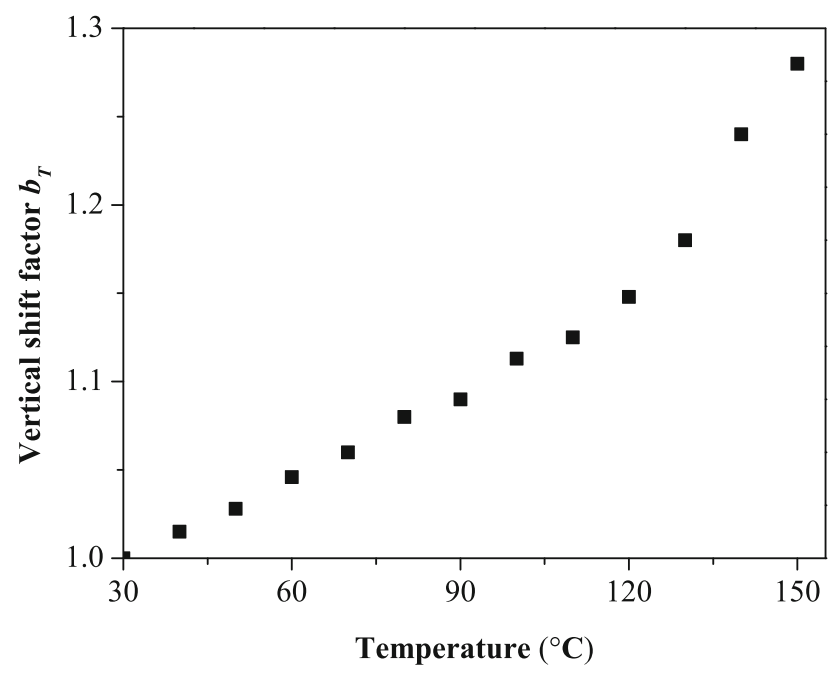

Fig. 8 Vertical shift factor $b_{T}$ for the $\mathrm{L}$ specimen

temperature dependency of $b_{T}$ (Fig. 8) showed an increasing trend in $b_{T}$ with increasing temperature and the values of $b_{T}>1$. The curve of vertical shift factor $b_{T}$ versus temperature exhibited two different slopes, lower/ higher than around $120^{\circ} \mathrm{C}$. The $b_{T}$ increased sharply when the temperature was more than $120^{\circ} \mathrm{C}$. According to Back and Salmén [39], the glass transition of lignin occurred at a range between 130 and $205{ }^{\circ} \mathrm{C}$ for dry wood. Therefore, the deviation from the threshold temperature $120^{\circ} \mathrm{C}$ was probably ascribed to the glass transition of lignin. The glass transition of lignin intensified the reorientation of cellulose microfibrils and caused the amount of increasing $b_{T}$ to be aggravated above $120^{\circ} \mathrm{C}$.

The TTSP was applied as soon as the continuity between individual creep curves in the ACP was satisfied. The corrected longitudinal data by the $J-T$ effect were used to construct a master curve; Fig. 9 depicts the

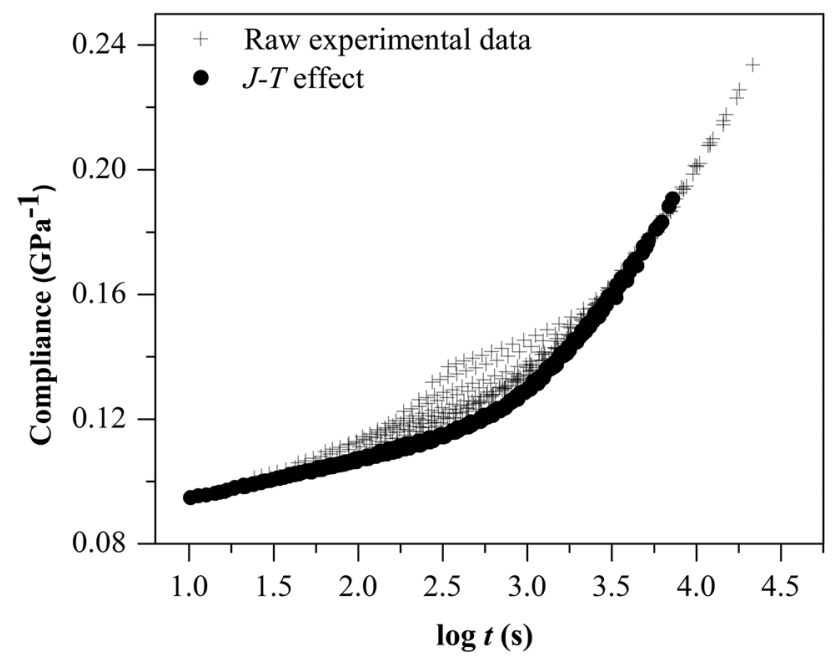

Fig. 9 The master curves of raw experimental data and corrected by the $J-T$ effect for the $\mathrm{L}$ specimen perfectly smooth master curve accounting for the $J-T$ effect. Furthermore, the temperature dependency of the horizontal shift factor after correction is represented in Fig. 5a. The temperature dependency of the horizontal shift factor $a_{T}$ plots for $\mathrm{L}$ specimen presented difference between raw data and data corrected by the $J-T$ effect: after the $J-T$ effect correction, a lower absolute value of $a_{T}$ was found. The WLF equation provided a better fitting with the horizontal shift factor than Arrhenius law after correction (Fig. 5a), and the parameters of the two models are listed in Table 1. As compared to the activation energy of raw data for the $\mathrm{L}$ specimen, the $J-T$ effect resulted in lower activation energy (Table 1). This indicated that considering the $J-T$ effect would reduce the internal friction of wood cell wall by making the molecular chain flexible, and the distortions of bond angles and chain rotations became easier.

\section{Creep model}

Master curves were developed for Chinese fir in tension using short-term creep tests for the $\mathrm{L}, \mathrm{R}$, and $\mathrm{T}$ specimens. Power law equations were then applied for each master curve using a nonlinear fitting procedure. Based on the approximately straight line of experimental data in the (transformed) ACP (Figs. 6 "R", "T", 7), the power law model was derived as in Eq. (7):

$J(t)=J_{0}\left[1+a \cdot t^{k}\right]$,

where $J_{0}$ is the initial compliance, $k$ the kinetic parameter and $a$ the estimated parameter. The model parameters $J_{0}$ and $k$ were directly identified from the ACP (Figs. 6 "R", "T", 7) and presented with $a$ in Table 2.

The creep model showed very good agreement between modeled and master curves for each specimen, as illustrated in Fig. 10. The variation of initial compliance $J_{0}$ among the L, R, and $\mathrm{T}$ specimens (Table 2) also confirmed the aforementioned orthotropic compliance. According to Douhá et al. [8], the kinetic parameter $k$ of five tropical species likely related to structural diversity, but the link between them was not clear. In this study, the creep model parameters also showed variation with grain orientation for Chinese fir. This opened expectations on future work

Table 2 Power law model parameters for Chinese fir wood in all orthotropic directions

\begin{tabular}{lllcl}
\hline Specimens & $J_{0}\left(\mathrm{GPa}^{-1}\right)$ & $k$ & $a \times 10^{-3}\left(\mathrm{~s}^{-1}\right)$ & RMS error $(\%)$ \\
\hline $\mathrm{L}$ & 0.09 & 0.51 & 11.17 & 0.00 \\
$\mathrm{R}$ & 3.33 & 0.28 & 1.99 & 0.00 \\
$\mathrm{~T}$ & 6.85 & 0.30 & 2.12 & 0.01 \\
\hline
\end{tabular}

$\overline{J_{0} \text {, initial compliance; } k \text { and } a \text {, power law parameters; RMS error, root }}$ mean square error between modeled and measured compliance values 

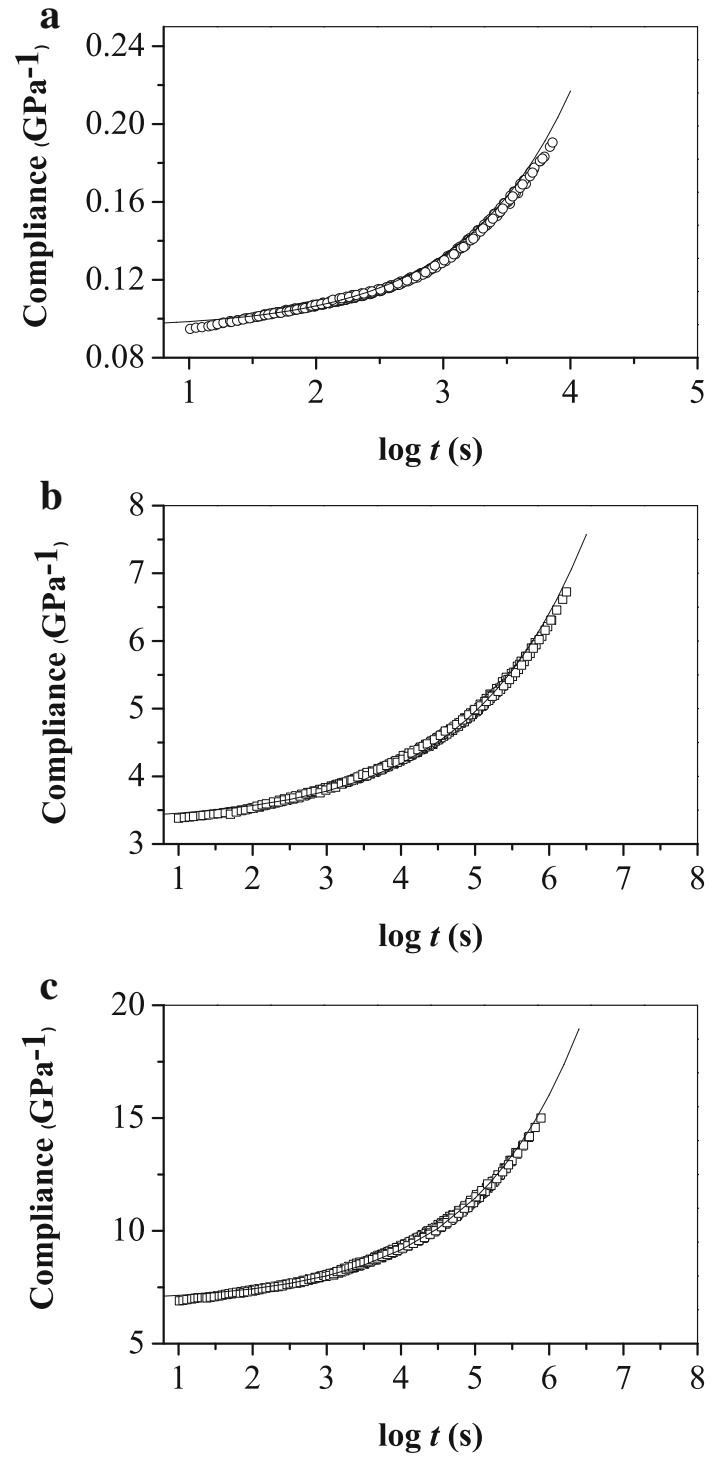

Fig. 10 Agreement between master curves (symbols) and power law model (solid line curves) determined for the L (a), R (b), and $\mathrm{T}$ (c) specimens

relying on the understanding of the physical meaning of the model parameters.

\section{Conclusions}

The validation of TTSP was a vital task prior to the practical application. In this study, a sequence of short-term creep tests for dry wood at $10{ }^{\circ} \mathrm{C}$ interval in the temperature range of $30-150{ }^{\circ} \mathrm{C}$ was conducted in the $\mathrm{L}, \mathrm{R}$, and $\mathrm{T}$ directions. The main conclusions are as follows:

- Creep compliance was dependent on temperature and orthotropic directions. Creep was accelerated with elevating temperature, resulting in reducing the time required for a given deformation.

- The overlapping curves of the $\mathrm{R}$ and $\mathrm{T}$ specimens were quite well matched than the $\mathrm{L}$ specimen for dry wood only using horizontal shift factor over the temperature range of $30-150{ }^{\circ} \mathrm{C}$. However, the compliance curve for the $\mathrm{L}$ specimen required an additional vertical shift factor to construct a smooth master curve because of the effect of temperature on longitudinal compliance.

- The creep model governed by a power law depicted the master curve for each specimen and showed the relevance between the model parameters and ACP data.

- Finally, the present work partially fills up the applicability of TTSP to wood rheological properties and provides the firsthand data on the anisotropic TTSP's applicability. In addition, the work successfully builds the rheological model in three grain directions to predict the orthotropic creep response.

Acknowledgements This research was sponsored by the National Natural Science Foundation of China (31570548).

\section{References}

1. Miyoshi Y, Furuta Y (2016) Rheological consideration in fracture of wood in lateral tension. J Wood Sci 62:138-145

2. Kaboorani A, Blanchet P, Laghdir A (2013) A rapid method to assess viscoelastic and mechanosorptive creep in wood. Wood Fiber Sci 45:370-382

3. Forest Products Laboratory (1987) Wood handbook. Agriculture handbook, vol 72. USDA Forest Service, Washington, DC

4. Bodig J, Jayne BA (1982) Mechanics of wood and wood composites. Von Nostrand Reinhold Company, New York

5. Navi P, Stanzl-Tschegg S (2009) Micromechanics of creep and relaxation of wood. A review COST Action E35 2004-2008: wood machining-micromechanics and fracture. Holzforschung 63:186-195

6. Chang FC, Lam F, Kadla JF (2013) Using master curves based on time-temperature superposition principle to predict creep strains of wood-plastic composites. Wood Sci Technol 47:571-584

7. Ma X, Jiang Z, Tong L, Wang G, Cheng H (2015) Development of creep models for glued laminated bamboo using the timetemperature superposition principle. Wood Fiber Sci 47:141-146

8. Dlouhá J, Clair B, Arnould O, Horáček P, Gril J (2009) On the time-temperature equivalency in green wood: characterisation of viscoelastic properties in longitudinal direction. Holzforschung 63:327-333

9. Wang F, Huang T, Shao Z (2017) Application of TTSP to wooddevelopment of a vertical shift factor. Holzforschung 71:51-55

10. Williams ML, Landel RF, Ferry JD (1955) The temperature dependence of relaxation mechanisms in amorphous polymers and other glass-forming liquids. J Am Chem Soc 77:3701-3705

11. Goodrich T, Nawaz N, Feih S, Lattimer BY, Mouritz AP (2010) High-temperature mechanical properties and thermal recovery of balsa wood. J Wood Sci 56:437-443

12. Kelley SS, Rials TG, Glasser WG (1987) Relaxation behaviour of the amorphous components of wood. J Mater Sci 22:617-624

13. Laborie MPG, Salmén L (2004) Cooperativity analysis of the in situ lignin glass transition. Holzforschung 58:129-133 
14. Placet V, Passard J, Perré P (2007) Viscoelastic properties of green wood across the grain measured by harmonic tests in the range $0-95^{\circ} \mathrm{C}$ : hardwood vs. softwood and normal wood vs. reaction wood. Holzforschung 61:548-557

15. Sun N, Frazier CE (2007) Time/temperature equivalence in the dry wood creep response. Holzforschung 61:702-706

16. Taniguchi Y, Ando K, Yamamoto H (2010) Determination of three-dimensional viscoelastic compliance in wood by tensile creep test. J Wood Sci 56:82-84

17. Ando K, Mizutani M, Taniguchi Y, Yamamoto H (2013) Time dependence of Poisson's effect in wood III: asymmetry of threedimensional viscoelastic compliance matrix of Japanese cypress. J Wood Sci 59:290-298

18. Kawahara K, Ando K, Taniguchi Y (2015) Time dependence of Poisson's effect in wood IV: influence of grain angle. J Wood Sci 61:372-383

19. Dastoorian F, Tajvidi M, Ebrahimi G (2010) Evaluation of time dependent behavior of a wood flour/high density polyethylene composite. J Reinf Plast Compos 29:132-143

20. Alfrey T (1948) Mechanical behavior of high polymers. Interscience, New York

21. Larsen F, Ormarsson S (2014) Experimental and finite element study of the effect of temperature and moisture on the tangential tensile strength and fracture behavior in timber logs. Holzforschung 68:133-140

22. Backman AC, Lindberg KAH (2001) Differences in wood material responses for radial and tangential direction as measured by dynamic mechanical thermal analysis. J Mater Sci 36:3777-3783

23. Bader TK, Hofstetter K, Eberhardsteiner JA, Keunecke D (2012) Microstructure-stiffness relationships of common yew and Norway spruce. Strain 48:306-316

24. Salmén L, Burgert I (2009) Cell wall features with regard to mechanical performance. A review COST Action E35 2004-2008: wood machining-micromechanics and fracture. Holzforschung 63:121-129

25. Kifetew G (1999) The influence of the geometrical distribution of cell-wall tissues on the transverse anisotropic dimensional changes of softwood. Holzforschung 53:347-349

26. Mishnaevsky L, Qing H (2008) Micromechanical modelling of mechanical behaviour and strength of wood: state-of-the-art review. Comput Mater Sci 44:363-370
27. Ferry JD (1980) Viscoelastic properties of polymers. Wiley, New York

28. Gamalath SS (1991) Long term creep modeling of wood using time temperature superposition principle. Dissertation, Virginia Polytechnic Institute and State University, Blacksburg, VA

29. Bond BH, Loferski J, Tissaoui J, Holzer S (1997) Development of tension and compression creep models for wood using the timetemperature superposition principle. For Prod J 47:97-103

30. Engelund ET, Svensson S (2011) Modelling time-dependent mechanical behaviour of softwood using deformation kinetics. Holzforschung 65:231-237

31. Bergander A, Salmén L (2002) Cell wall properties and their effects on the mechanical properties of fibers. J Mater Sci 37:151-156

32. Salmén L (2004) Micromechanical understanding of the cell-wall structure. C R Biol 327:873-880

33. Gierlinger N, Schwanninger M, Reinecke A, Burgert I (2006) Molecular changes during tensile deformation of single wood fibers followed by Raman microscopy. Biomacromol 7:2077-2081

34. Salmén L (2006) Ultra-structural arrangement and rearrangement of the cellulose aggregates within the secondary cell wall. Proceedings of the Fifth Plant Biomechanics Conference. STFIPackforsk, Stockholm, pp 215-220

35. Kamiyama T, Suzuki H, Sugiyama J (2005) Studies of the structural change during deformation in Cryptomeria japonica by time-resolved synchrotron small-angle X-ray scattering. J Struct Biol 151:1-11

36. Landel RF, Nielsen LE (1993) Mechanical properties of polymers and composites. CRC Press, New York

37. Tajvidi M, Falk RH, Hermanson JC (2005) Time-temperature superposition principle applied to a kenaf-fiber/high-density polyethylene composite. J Appl Polym Sci 97:1995-2004

38. Maiti A (2016) A geometry-based approach to determining timetemperature superposition shifts in aging experiments. Rheol Acta 55:83-90

39. Back EL, Salmén NL (1982) Glass transition of wood components hold implications for molding and pulping processes. Tappi J 65:107-110 